Tourism and the Value System .... (Sharma)

\title{
Tourism and the Value System: An Impact Assessment from Socio-cultural Perspective
}

Ramji Sharma

\section{Abstract}

The contemporary world has given a high priority to the development of tourism for the reason that it is considered as an export business without actually sending any tangible products out of the boarder. Beside its economic gain, its effects and implications appear in myriad of forms and guises both in pros and cons. Some of them are latent just performing as instigating agents while some are manifest functioning proactively; some are momentary and some are enduring too. From socio-cultural dimension, tourism appears as a powerful agent of diffusion, acculturation and assimilation. It influences, directly or indirectly, each and every aspects of the host society. The value system of the tourist receiving community can not remain in isolation. This study covers the impacts caused by the development of tourism business over the selected components of the value system of host societies viz. Lakeside of Pokhara and Sarangkot of Kaski.

[Key words : tourism, socio-cultural impact, value system, host community]

\section{Preamble}

The contemporary world has endorsed the growing interaction and interpenetration between the existing, relatively interdependent, social system. The world is rapidly becoming a global village. No afar islands or obscure archaic tribal settlements manage to preserve their isolation. The globalization has easy reaches in these settlements today. Tourism itself is a progeny of the globalization. Tourism, by its virtue, is truly a social phenomenon for it mostly involves travel, and travel in general is a group endeavor which includes contact and connection with various human societies. Social exchange is the common occurrence among travelers for various reasons, be it a lonely travel or travel in families, couples, tour groups or as delegates to a conference. A traveler may buy something while on a trip or seek information or just exchange pleasantries with fellow tourists or residents. These encounters are social interactions which provide impressions and images for each person involved. Tourism as a commercial 
fragrance needs society to cater its needs. As tourism is eagerly sought for by the developing nations as an important source of revenue, it may provoke serious disruptions and cause ultimate long-range implications on receiving societies. The general belief is that the contact with other people generates some kind of change. That sort of change may appear with positive attributes from one perspective but may appear with absolutely negative and harmful dispositions from the other dimension. And those effects can be simple or complex, short-term or long-term, momentary or enduring.

For many travelers, cross-cultural exchange with fellow travelers or residents of destinations is exactly what makes tourism exciting and astounding. Tourism may leave its impact on varied aspects of man's life. Tourism and the resultant recreational activities besides the economic gains have an impact on the sensitive natural environment as well as the delicate social fabric of the local community. The growth of tourism may produce both threats and opportunities on the vast scale for societies and socio-cultural ancillaries. Tourism per se is a strong carriage of diffusion and acculturation. There are instances of tourism that has caused the existence of wide sociocultural differences between different countries and sometimes between different places within the same country. Tourists do not visit different places alone but they travel with their own beliefs, values and behavioral modes that may be termed as 'cultural baggage' (Page et al, 2001:277). The scope of mixing the cultures is great when such cultural baggages come into contact with other social settings. In this respect, tourism is all about people and how people as tourists interact with other locations and peoples, engaging in experiences that may influence their own or the host community attitudes, expectations, opinions, lifestyles, values, morals, modes of expressions and community structures.

Rao (2002:193) writes that culture consists of the words the people use or the language they speak, the beliefs they hold, values and virtues they cherish, habits they follow, rituals and practices that they do and the 
ceremonies they observe. He adds that it also includes our customs and tastes, attitudes and outlook, in brief, our ways of acting, feeling and thinking. Therefore, each face or unit of the society has a complete set of culture maintaining its own value system, beliefs, ideas, attitudes, perceptions and habits. For instances, the metros have a different culture and, therefore, have different tourism implications whereas the folks in the countryside have different culture having different kind of relationship with tourists. But the concept of culture has many definitions and interpretations. In social settings, it is often used broadly to represent entire ways of life. Included in such ways of life are rules, values, and expected behaviors. At its most basic level, culture can be seen as the shared products of a society that includes values and beliefs, ideas and ideologies, morals and manners, customs and traditions and other material and non-material environments created and developed by men as a member of society.

Value as an integral unit of culture is an abstract concept that reflects ideals and visions of what society should be. Values are shared ideas and beliefs about what is morally right or wrong, or what is culturally acceptable and desirable. Values are thus the measures of decency and desirability of a society. Such values often carve the expected behaviors and rules of the social stance. These rules are accepted ways of doing things and represent guidelines for how people should conduct themselves and should act towards others. Every society exerts its pressure upon people to conform to the norms and values. Norm implies a sense of social obligation. It lays down a standard of behavior which everyone ought to follow. And values are criteria people use in assessing their daily lives, arranging their priorities, measuring their pleasures and pains, choosing between alternative courses of action. The fact to remember here is that different societies have distinct and different values. Values of different societies may conflict with one another. It is often likely to find multiple, overlapping and sometimes even opposing value systems in the same society. Switching from one value system to the other in long run is also possible. The dominant values often 
influence and stipulate the behavior of the people to a great extent. Thus, values and norms are dynamic, not static. Tourism can be a powerful agent to induce values and norms of a society into dynamism which may beget ranges of change and modification in society and culture. Many impacts of tourism over the host society appear relatively quick while others emerge slowly and gradually. Social and cultural implications normally fall into this second category and, over time, those implications transform into sociocultural changes with enduring solid foundation. However, some sociocultural impacts tend to manifest very quickly - may be positive or negative for the host community.

\section{Objective \& Research Methods}

The general objective of this work was to investigate and analyze the impacts of tourism over the value system of host communities which depend more or less on tourism business. And specifically, this study was to analyze the impacts and implications of tourism business over the selected seven components of value system of the host communities -prostitution, crime, drug abuse, alcoholism and gambling, behavioral mode and labor division.

Based on above mentioned objectives both exploratory and descriptive methods were employed in the study. The student's t-test based on matched paired observation with substantial support of correlation and standard deviation techniques were used to test the established hypotheses. Tourism is the main economic resource of Pokhara and its vicinity, especially for the community at the northern catchments of Lake Fewa (called Baidam) and the residents near the Sarangkot Tower of Kaski. Concerning the importance of tourism and its influence, these two settlements of the region are different and distinct, and therefore selected as the research zone for this study. Hoteliers, restaurateurs, travel and tour operators, trekking agents, art/crafts/curios and community households of Baidam catchments (approximately 1,500 m north from the Fewa Lake, Pokhara, Nepal) and the similar segments in Sarangkot (approximately 1,000 m around the 
Sarangkot-Tower, Kaski, Nepal) were selected as the population universe for this study. and the hoteliers as well as other residents of Sarangkot The selection of the research zone was not by default but after a deliberate consideration of the heterogeneity of socio-cultural settings with ethnographic significance and the frequency of host-guest contacts and interactions, the sampling areas had been curbed in a frame.

The total of 58 informants was chosen randomly from Lake Side selecting 15 percent from each respondent's category operating in the study zone (restaurants and bars-7, travel and tours operators-6, trekking agents-4, hotels-23 and art/craft/curios/souvenirs-6 and12 respondents from the community households). In case of Sarangkot, a total of 21 respondents were selected to configure the size of informants taking 7 from hoteliers (hotel owners), 5 from among the employees working in these hotels in different capacities and other 9 respondents from the rest community. These two separate settlements, one with the essence of urban sprawl and the other with a typical setting of a rural milieu with suburb fragrance, have their own specialty and uniqueness which facilitated the researcher to have cross comparison and multiple understanding of the impacts and implications of tourism. Both primary as well as secondary data have been utilized in this study. However, the study was mainly based on primary data collected from the sets of questionnaires, structured and unstructured schedule interview, personal observations, opinion survey (tourism personalities) and telephonic conversation with tourism experts with minimal backing of the secondary information. The computer aided SPSS program was used to obtain the various results like standard deviation, coefficient of correlation and the value of student's t-test. Manual processing and analysis was also done for some qualitative data to interpret and construe the qualitative attributes of the information.

\section{Theoretical Framework}

The outcome of tourist-host relationship in the destination can be seen in the guest as well as in the host community's quality of life, value system, 
labor division, family relationships, attitudes, behavioral patterns, ceremonies, creative expressions etc. This study has only covered the implications of tourism over the host community as perceived by residents / stakeholders skipping over the same kind of possible implications over the tourists. The seven aspects of value system were considered as variables to assess the impacts and implications of tourism in this study as shown below:
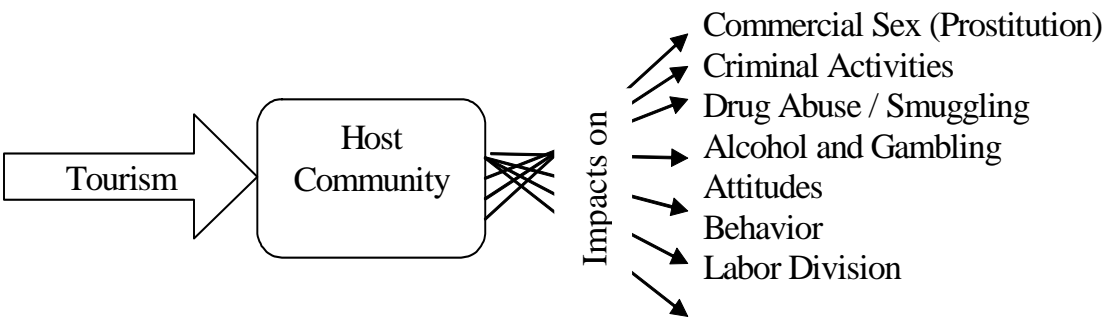

Fig 1.1 Tourism, Community and Selected Variables

\section{THE ASSESSMENT}

\section{Impact of Tourism over the Commercial Sex (Prostitution)}

Sex has for long been the $4^{\text {th }} \mathbf{S}$ in tourism sector, the other being Sun, Sea and Sand as often utilized in the selling of a holiday product. Tourism associated with prostitution or what is called sex-tourism has assumed alarming proportion in many South-East Asian countries. Sex tourism, massage parlors, drug peddling and bride buying have become interlinked particularly in the Third World countries with some form of tourists. Prostitution resulting from the tourism industry has reached the crisis level at destinations such as Bangkok (Thailand), Manila (Philippines), Bali (Indonesia), Vietnam, Malaysia, the Caribbean Island and parts of East Africa (BBC’s various programs- Asia Today). Governments in many countries are encouraging sex-tourism as an easy means of acquiring foreign exchange. Amsterdam, a popular European city of the Netherlands has a well-known "red light zone" which is a cultural icon in itself and focuses for tourist activity. The government of Holland (the Netherlands) has demarcated the particular area as the red-light zone where one can freely 
engage in sexual activities, enter into coffee shops (places to personally consume hashish and varieties of narcotic and sedative drugs but possession is illegal), go for live sex shows, visit the sex museums and sex parlors where one can openly experience the élan of sex.

The ethos of Amsterdam has an enticing appeal for people even from some conventional Asian societies (in sex-matters) and therefore the Japanese, Korean, Chinese, Indian and Pakistani visitors were found strolling around the red-light streets, sex-parlors, sex shows and sexmuseums in Amsterdam, the Netherlands (Researcher's Personal Observation, 2004). Therefore, it is believed that the tourists (especially western) already been to Amsterdam have the similar mind-set and thus expect the easy availability of sex-parlors in other tourist-destinations as well. Ghosh (2002:174) writes that brothels catering to tourists flourished in South-East Asia under a variety of guises by the 1970s. Massage parlors, sex-shows, yoga bars, health clubs, cocktail lounges - all existed with the sole purpose of meeting the sexual needs of visitors. Sex-tourism is not a major factor of tourism in Nepal. Yet, unfortunately symptoms have started emerging in some places like Thamel (Kathmandu) and Lakeside (Pokhara). The study has showed that there is a positive correlation between tourism and prostitution in Pokhara.

Most of the respondents believe that sex related activities have been increasing day by day in Lakeside as well as in Sarangkot. Among the total respondents, 60.34 percent of them accepted that the sex business in Lakeside region is flourishing in different guises like massage parlors, discos and dance-clubs. Nightclub cabarets and shower dances in some restaurants of Lakeside corroborate this fact in Pokhara. These places offer erotic dances for the visitors. The dancers mostly girls captivate guests by maneuvering erogenous zones of their body which often remain more or less naked. 
The response is incredibly high in case of Sarangkot for the fact that 80.95 percent respondents noticed a kind of thrive of sexual activities in this belt. But most of the respondents in Sarangkot argued that the sex workers already make arrangements with the clients in the Lakeside region and ascend to the hill in the evening to spend a night or two in hotels available in Sarangkot. This proposition proves that the environment of the hotels and lodges near the Sarangkot tower is also supportive and favorable for sex and other self indulgence. The respondents of Lakeside unanimously claimed that the cabaret and shower dancers are among the easily available sex-workers for the tourists in this area. The respondents also agreed that tourism has created an environment which attracts prostitutes and their clients in this area. They also remarked that the streets of Lakeside in the evenings of the peak seasons are often thronged by curious tourists (especially male) who wish to find the local girl for the night partner. Out of the total respondents in the Lakeside, 55.17 percent felt that tourists often find in relax attitude towards sex in the evening where as 38.10 percent expressed the same feeling in Sarangkot. Ghosh (2002:176) writes that the tourists often want entertainment in the evening and "entertainment" in the western sense is impossible without gambling and flesh trade. The study reveals that the tourists' demand for sex has encouraged the flesh trade (prostitution) in these destinations. In spite of this, a few respondents (5.17 percent) in Lakeside have the view that tourism plays a positive role to control the sex business (flesh trade) in the tourists' destinations. Similarly, 31.03percent and 34.48percent respondents in Lakeside expressed that tourism provides social awareness about prostitution and Sexually Transmitted Diseases (STDs) respectively.

\section{Impact of Tourism over the Criminal Activities}

It is alleged that tourism generates crime. But there is no universal agreement on whether tourism leads to increased crime in a locality. Nonetheless, there are a number of instances to have criminal activities in tourism destinations. Tourists are vulnerable because they are in unfamiliar 
surroundings, and may be carrying cameras, camcorders, cash and credit cards which are valuable commodities in the black market. Tourists become easy marks for robbers and other offenders because they are readily identified and are usually not very well equipped to ward off an attack. They normally do not have knowledge about dangerous areas or local situations in which they might be defenseless to violent crimes. On the other side, there are a number of instances of tourists engaging in crime and illicit activities such as violent and drunken behavior, drug smuggling and sex tourism in some destinations.

These activities undoubtedly encourage violent and criminal activities in the destination. Criminal activities in and around the destination result in bad publicity and create a negative image in the minds of prospective visitors. According to Page et al (2001:283), certain areas of the world have a sort of recognition for posing threats to tourist well-being, such as Jamaica and Florida. In the late 1980s and early 1990s, several high-profile cases of tourist attacks in Florida provoked fear among the visitors. Pizam et al (1982:7) found that tourism expenditures have a negligible effect on crime. They suggested that tourism, however, could be considered a potential determinant of crime negatively affecting the quality of the environment, the tourist industry cannot be held responsible for the occurrence of crime. But one must be aware that tourists are potential targets of crime. Protecting them from offenders is essential to the survival and growth of the industry. In an attempt to attack tourists, crimes have developed. Through the escalation of conflict between the host population and tourists, many criminal activities proliferate. Tourism creates situations where gains from crime may be high and the likelihood of detection small. Stealing is a common criminal activity in tourism spots. In spite of this fact, the perception of the people living in Lakeside area is a bit different.

Only 15.52percent people of Lakeside felt that the environment created by tourism is highly supportive for criminal activities. And only 9.52 percent people of Sarangkot opined the similar view in this favor. About 64 percent 
respondents (the figure is significantly important) in Lakeside and about 29percent respondents in Sarangkot said that the environment in tourism destinations is slightly supportive for criminal activities like theft, murder, brawl and rape. There is a big number of people (51.72percent in case of Lakeside and 71.43 percent in case of Sarangkot) who did not see any role of tourism for the encouragement of criminal activities. They believed that the jobless youths and waifs and strays (Khates) who come in these areas from surrounding rural settlements are tempted by the luxurious life of the tourists which motivate them to steal the goods and money of tourists to fulfill their pent up desire. Despite this, 15.52 percent respondents of Lakeside argued that the development of tourism plays a significant role to control criminal activities in the destination.

\section{Impact of Tourism over the Drug Abuse / Smuggling}

Tourism is not a simplistic and naïve as the term might seem to connote as such. A superficial view of tourism activity may elaborate it as simply movement of people from one place to another inspired by any of the purposes but, underneath, it is rather a multifarious of various interrelated and interacting processes. The study shows that there is significant relation between tourism and the abuse or smuggling of drugs. Some respondents (15.25percent) of Lakeside catchment area opined that where there is prostitution, there is drug smuggling too. And 28.57 percent informants in Sarangkot have given the same expression. It has already described above that the growing trend of prostitution in both the settlements - Baidam (Lakeside) of Pokhara and Sarangkot of Kaski. Provided that the statement given by the respondents is true regarding the relation between the flesh trade (prostitution) and drug, there is a growing trend of drug abusing and smuggling in both the settlements.

The cent percent (100percent) respondents of Sarangkot perceived tourism as a culprit of encouraging the drug addiction in this community. About 64percent people of Lakeside also held the similar perception. Only 10.34percent people in Lakeside supported for the insignificant relationship between tourism and the drug peddling. However, no one in Sarangkot was ready to support that the relationship between tourism and the drug 
abuse is insignificant. There is no other economic activity that cuts across so many sectors, levels and interests as tourism. About 32.76 percent people of Lakeside opined that tourism helps society make aware of drug abuse. A significant number of respondents perceived visible and transparent negative impacts of tourism on the street children. Almost 61.90 percent informants in Sarangkot and 31.03 percent informants in Lakeside asserted that some street children are being used by tourists for the dealings of drugs and hashish (Ganja). Without any reliable logic, 10.34 percent people of Lakeside told that the development of tourism has discouraged the illegal use of drug and marijuana in this locality.

\section{Impact of Tourism over the use of Alcohol and Gambling}

It is difficult to make precise judgment of the extent to which tourism causes social and cultural change because it is just one force of change which functions in the host society. It is also apparent that in some cases tourism has been developed at the expense of the host community, where economic gain has been placed at higher priority than the well-being and integrity of the local people. Almost 75.86 percent people of lakeside and 71.43 percent people in Sarangkot believed that tourism creates an ambiance which induces people to consume alcohol. Gambling often accompanies alcoholism. Gambling has always been a popular form of recreation for well-off tourists. It is said that Nevada has been the leader in gambling, which has made tourism the leading industry in the United States.

The fact is that the well-to-do people enjoy gambling as an entertainment option in their lives and the gambling places like casinos are full of entertaining facilities with varieties of drinks which are served complementarily in those places. There are some people, almost 5.17 percent, in Lakeside who do not find any connection of tourism with gambling and alcoholism. Almost 40percent people of the total respondents believed that tourism has increased the consumption of alcohol but did not realize any relation of tourism with gambling. This fact has revealed that the incidence of gambling is less than the incidence of drinking in Lakeside and Sarangkot catchments. It should be noted here that the null hypothesis for this has been accepted. This signifies that the popularity of alcohol and 
Himalayan Journal of Sociology \& Anthropology-Vol. III

gambling in these communities may be rooted more to other factors than tourism.

\section{Impact of Tourism over the Attitudes of the Local People}

Attitudes are somewhat like intellectual, emotional, and behavioral responses to events, things, and persons which people learn over time. The presence of visitors in a country affects the living patterns of indigenous peoples. The way visitors behave themselves and their personal relationships with citizens of the host community often have a profound effect on the mode of life and attitudes of local people. Almost 83 percent people of Lakeside felt that tourism has taught them to be more hospitable than ever before. About 81percent people of Sarangkot also had the similar selfassessment. The field research shows that the people of these communities are now more tolerant, co-operative and open-minded. But some respondents (22.41percent - Lakeside and 38.10percent - Sarangkot) also admitted that tourism has developed some negative attributes in them as well like selfishness and money mindedness.

\section{Impact of Tourism over the Behavioral Pattern}

Tourism is one of the most vibrant, growing and economically useful activity in the world having wide cultural and social propositions. Tourists bring their life style, habits, dressing code, food habits, merry making manners, attitudes and behaviors with them when they visit different places. This is the reason which keeps the tourist's and resident's attitudes in disagreement with each other. The most striking feature of tourism is that it infuses a large number of small effects which, individually, appear to be almost insignificant but together have far-reaching implications. The aftermaths of tourism on social as well as individual behavior are slow but penetrating and enduring. One of the forefront impacts of tourism on behavior of the people of destinations is being materialistic. About 67.24percent people of Lakeside admitted that money drives their behavior and treatment. They run after money and exhibit their behavior accordingly. In Sarangkot, 71.43percent people hold the same inference. 
Majority of the people (89.66percent) in Lakeside do not hesitate to admit that they present themselves differently with tourists, perhaps with special attention and priority. They exhibit in this way just for the sake of financial gains. Very interestingly, 90.48percent people in Sarangkot retained the identical feelings with this. None of the hoteliers and restaurateurs (0percent in both settlements) are ready to give attention and priority to the local people. Only a few people (10.34percent) in Lakeside were in favor of the equal treatment to the tourists and the local people. Almost all the respondents in both the communities agreed that there is high discrimination of treatment for the foreign visitors and the domestic visitors in hotels and restaurants.

\section{Impact of Tourism over the Labor Division of the Host Community} According to Page et al. (2001:265), tourism creates three types of employment. (a) Direct - jobs created as a result of visitor expenditure and directly supporting tourism activity (hotels for example), (b) Indirectjobs created within the tourism supply sector but not as a direct result of tourism activity and (c) Induced - jobs created as a result of tourism expenditure as local residents spend money earned from tourism. Tourism, in itself, is a labor intensive industry. Tourism may offer jobs for skilled, semi-skilled and even unskilled people. Therefore, most of the people of the tourist destinations entirely depend upon the tourism for their earnings. About 51.72percent respondents of Lakeside experienced that increasing economic dependence upon tourism has altered the traditional job structure and roles in the community, sometimes creating more new jobs for women than men. Almost all hotel-kitchens have male chefs only. But only 19.05percent people of Sarangkot experienced this type of implications over their community. At the same time, some of the respondents of both the settlements stated regrettably that many of these jobs are menial and underpaid. Employment of local people will generally be based on the local skill. In most cases, there will be few managerial posts in local tourism development but many jobs requiring minimal skill - low paid and little reward. Managerial grade jobs may be advertised across a wide geographic 
area to attract well-qualified and experienced candidates which promotes local frustration and alienation.

Despite this fact, 68.97percent respondents of Lakeside and 80.95percent of Sarangkot have also affirmed evidently that the role of gender has been changed in their society due to the development of tourism. There are involvements of more women in the tourism business now than ever before. Women are being more open and extrovert. They have begun to take part in decision making process as well. Almost 26percent informants of Lakeside catchments (and 9.52percent of Sarangkot) have observed that the demarcation of the professional line has been gradually vanishing in their community because of the development of tourism activities. The community people exhibit a kind of respect for every profession irrespective of its nature.

\section{Test of Hypotheses}

The following seven null hypotheses were tested in this research work. Null hypotheses $\left(\mathrm{H}_{\mathrm{o}}\right)$ were rejected when the obtained value of $\mathrm{t}$-test $\left(\mathrm{t}_{\mathrm{o}}\right)$ exceeded the table value $\left(\mathrm{t}_{\mathrm{v}}\right)$ at 5percent level of significance and the other way round for the acceptance of them.

$H_{o}$ : There is no significant relationship between the tourist-host encounter and the level of prostitution in the host community.

$H_{o}$ : There is no significant relationship between the tourist-host encounter and the level of criminal activities in the host community.

$H_{o}$ : There is no significant relationship between the tourist-host encounter and the level of drug abuse and smuggling in the host community.

$H_{o}$ : There is no significant relationship between the tourist-host encounter and the use of alcohol and gambling in the host community.

$H_{o}$ : There is no significant relationship between the tourist-host encounter and the attitudes of the people of host community.

$H_{o}$ : There is no significant relationship between the tourist-host encounter and the behavioral pattern of the people of host community.

$H_{o}$ : There is no significant relationship between the tourist-host encounter and the traditional labor division in the host community. 
Tourism and the Value System .... (Sharma)

The influence and implication of tourism over the value system of host community was evaluated by testing the following selected constituents of the value system. 
The results presented here clearly say that there are no grounds of accepting the null hypothesis. There is only one acceptance of the null hypothesis (alcohol and gambling) out of seven tests. However, it is very difficult to accept this when the values of standard deviation and correlation coefficient are considered. It means the respondents are unaware of the latent implications of tourism over the consumption of alcohol and increasing trend of gambling in their communities. The overall results obtained from the test underline the reality that the value systems of the host communities are not free at all from the influence of tourism.

\section{Findings and Conclusion}

Though tourism is a late-coming prodigy in Nepal, yet its economic benefits have gained high measures in the national economy. Tourism as a smokeless industry is the most promising and prospective sector for the economic development of Nepal. It has been argued frequently that tourism does not only despoil cultures but also revives culture and gives added value to them, both intellectually and economically. The enhancement of tourism may be symbiotic in relation to the visitors and visited. However, its development is like the two blades of a scissors. On the one hand, it can highly be acknowledged as an economic savior while on the other, it can be a dire agent of social, cultural as well as environmental degradation unless it is nurtured strategically. The progression of tourism has a strong foothold of socio-cultural change, development, diffusion, acculturation and assimilation.

It can be a means of cultural revitalization too. It may sometime preserve and rejuvenate the local arts and cultures in the interests of tourism and can also revive the once dying out arts, cultures and other artifacts by providing financial support and provoking socio-cultural dignity and the sense of cultural pride. However, the commoditization of cultural components for the touristic purpose may trivialize them fading their authenticity and aesthetic spirituality. The fact is that tourists not only bring money to the 
destination; they also carry an explicitly visible and demonstrating life-style along with them. Their outfits, food habits and entertaining style all bring some novelty and distinctiveness to the area of their visit. The effect of tourism might appear in various forms and guises. Tourism, though, considered an economic enterprise in general, is a complex milieu of the multiple interrelated dimensions of human issues. Human beings, by natural instinct, are very curious for any new things they come across. Their everinquisitive behavior drives them to adopt new styles and habits from strangers even just for the taste sake. Social and cross-cultural interactions have been the intrinsic motivational aspects for many people in the travel process.

This study gives surety that the influence of imitation on local people by observing the life style of tourists - called demonstration effect- is more visible and perceptible in Lakeside than in Sarangkot catchments. Some people of Lakeside would like to go to the pubs and discotheques to entertain in the leisure time where they dance and relax with liquor especially in the evening. But the number of female respondents having the same mind-set in this connection is negligible. Some of them would like to have a short hike in their free time but the number to go for short hike in the free time in Sarangkot is relatively more perhaps due to the absence of pubs and discotheques there. Though sex tourism is not the major appealing factor of Nepalese tourism, yet it has been thriving in some places like Thamel (Kathmandu) and Lakeside (Pokhara). The growing demand of Nightclub cabarets and sex appealing Shower dances in Lakeside endorses this fact in Pokhara. These places offer erotically exiting dances from the dancers who often prefer to pose in transparent bikini. More than 60percent respondents in lakeside believe that this environment definitely encourages sex business (prostitution) in these catchments. Sarangkot does not have those kinds of nightclubs. However, almost 81 percent respondents noticed thriving prostitution in this belt with tourists (both domestic and foreign) as clients. 
The study revealed that the sex business (flesh trade) has special relation with drug-smuggling too. Prostitution and drug smuggling are found growing side by side in Lakeside. Tourist areas are the fertile grounds for both kinds of dealings. Almost all the informants make out the noticeable drug peddling (narcotic/sedative) in Sarangkot. Even school-going children in Sarangkot and the stray-children (khates) in Lakeside are found involved in Ganja (hashish) dealing. Pederasty with street boys (by tourists) is the other observation in Lakeside by the significant number of respondents. The other factors which accompany prostitution and drug-smuggling are crime, alcoholism and gambling. These types of activities are found on the rise in Lakeside; however the intensity is observed relatively less in Sarangkot. Tourists visit different places with their unique cultural baggage that keeps their attitude in disagreement with residents. The repercussions of tourism on social as well as individual behavior are slow but penetrating and lasting. It infuses a large number of small effects in a bowl. They individually appear to be almost insignificant but together appear with synergic bang. As per the perception of respondents, tourism has imprinted individualistic behavior among the people of Lakeside community which will eventually drive people towards the nuclear family. But this effect is not in flash in Sarangkot yet. The development of tourism has influenced the local people over their attitudes too. It has taught them to be more open, tolerant, hospitable, co-operative and a bit extravagant than before.

Tourism has changed the traditional labor division of the society. It has created more jobs for women than men in restaurants and front desks, and on the other side, almost all hotel kitchens in Lakeside have male chefs today. But the family-run hotels of Sarangkot still depend on female members for kitchen activities. There is a perceived concept that tourism sometime contaminates the morality and ethical bubble of the host residents. A kind of observable discriminating treatment is felt by the respondents in both the settlements for the foreigners and domestic visitors in hotels and restaurants. Perhaps this tendency has cropped up among hoteliers and 
restaurateurs due to their exclusive and intrinsic drive which is not other than the monetary advantage. As in western societies, the culture of these destinations apportions great emphasis on material success. The financial gains are the sole motives to treat foreign tourists differently assuming them as non-recurrent lucrative opportunities. The above discussed propositions clarify that the impacts of tourism are likely to be more in the destination which receives more tourists with longer duration of stay. The longer the tourists' stay in the destination, the more will be the encounters and interactions with the local community. A prolonged occurrence of such encounters may lead to a situation where the individuality and identity of the host environment gets mingled and may eventually be replaced by a new hybrid culture. Pace of tourism development is the other factor to vary the level of influence. Therefore, the socio-cultural impacts and implications are more obvious and detectable in Lakeside than in Sarangkot.

\section{References}

Bottomore, T.B. (1986). SOCIOLOGY- A guide to problems and literature. New Delhi: S. Chand and company Ltd.

Fridgen, Joseph D. (Dr.), (1996). Dimensions of Tourism. USA: Educational Institute, American Hotel and Motel Association.

Ghosh, Bishwanath (Dr.) (2002). Tourism and Travel Management. New Delhi: Vikash Publishing House Pvt Ltd.

Gibaldi, Joseph (ed.) (2000). MLA Handbook for Writers of Research Papers. New Delhi: Affiliated East-West Press Pvt Ltd.

Goeldner, C. R., Ritchie, J. R. B. and McIntosh, R. W. (2000). TOURISM Principles, Practices, Philosophies. New York: John Wiley and Sons, Inc.

Gupta, S.P. (1992). STATISTICAL METHODS. New Delhi: Sultan Chand and Sons Publishers.

Kothari, C. R. (2002). RESEARCH METHODOLOGY Methods and Techniques. New Delhi: Wishwa Prakashan 
Mathieson, A. and Wall, G. (1982). Tourism: Economic, Physical and Social Impacts. UK: Longman

Page, J. S., Brunt, P. and Busby G. (2001). Tourism: A Modern Synthesis. UK: Thomson Learning.

Pizam, A., Reichel, A. and Shieh, C. F. (1982). "Tourism and Crime: Is There a Relationship?” Journal of Travel Research, (PP 7-10), Vol. 20 No. 3.

Rao, C. N. S. (2002). SOCIOLOGY Primary Principles. Delhi: S. Chand and Company Ltd.

Ritzer, George (1992). Sociological Theory. New Delhi: McGraw Hill Company Inc.

Sharma, Ramji (2005). Socio-cultural Impacts of Tourism on Host Community: A Case of Pokhara and its Vicinity. MA Dissertation, Sociology/Anthropology Dept., PN Campus, T.U., Nepal.

Theobald, William F. (Ed), (2001). Global Tourism. UK: ButterworthHeinemann.

Wolff, H. K. and Pant, P. R. (2002). A Handbook for Social Science Research and Thesis Writing. Kathmandu: Research Division, T. U., Nepal. 